Available online on 15.03.2018 at http://jddtonline.info
Open Access to Pharmaceutical and Medical Research
commercial use, provided the original work is properly cited

Open $O_{\text {Access }}$

Research Article

\title{
ANTIHYPERGLYCEMIC ACTIVITY OF PITHECELLOBIUM DULES PLANT EXTRACTS ON BLOOD GLUCOSE LEVELS OF STREPTOZOCIN- INDUCED DIABETIC RATS
}

\author{
Upadhayay Ashutosh*, Kumari Sadhana, Shalini, Govindaswami Jayabalan \\ Alwar Pharmacy College, North Extension, MIA, Alwar, Rajasthan, India-301030
}

\section{ABSTRACT}

Background: The prevalence of diabetes mellitus continues to rise worldwide and treatment with oral hypoglycemic drugs leads to numerous side effects and huge monetary expenditure. Therefore active research on identification of new antidiabetic drugs with minimal side effects from medicinal plants is a challenge according to WHO recommendations. In this aspect, the present study was undertaken to evaluate the antihyperglycemic potential of Pithecellobium dulesplant in streptozotocin (STZ) induced diabetic rats.

Methods: Diabetes was induced in male wister rats by intraperitoneal administration of STZ ( $45 \mathrm{mg} / \mathrm{kg}$. b.w.).Fasting blood glucose (FBG) levels were measured by glucose-oxidase \& peroxidase method. The statistical analysis of results was carried out using and one-way analysis (ANOVA) followed by Student t-test.

Results and Discussion: Antihyperglycemic potentials of plant of Pithecellobium dules extract has been investigated at the doses of 150,300 and $600 \mathrm{mg} / \mathrm{kg}$ body weight orally administered to streptozocin-induced diabetes male wistar rats. Treatment of streptozocin diabetic male wistar rats with the extracts caused a significant $(\mathrm{P}<0.01)$ reduction in the blood glucose levels. The highest activity resides at the dose of $600 \mathrm{mg} / \mathrm{kg}$ body weight with meanpercentage blood glucose level change of $55.32 \%$ after 6 hours of extract administration while the other two doses 150 and $300 \mathrm{mg} / \mathrm{kg}$ have blood glucose level change of $40.45 \%$ and $47.14 \%$ respectively after 6 hours of extract administration. This result suggests that the Pithecellobium dules plant extractspossess antihyperglycemic effect on streptozocin-induced diabetic male wistar rats.

Conclusions: The plant extract is capable of managing antihyperglycemia and complications of diabetes in STZ induced diabetic rats. Hence, this plant may be considered as one of the potential sources for the isolation of new oral anti hypoglycemic agent(s) Keywords: Antihyperglycemic activity, Streptozocin, Pithecellobium dules, Diabetes mellitus

Article Info: Received 16 Jan, 2018; Review Completed 5 March, 2018; Accepted 7 March, 2018; Available online 15 March, 2018

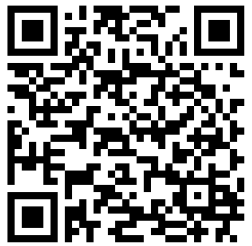

Cite this article as:

Upadhayay A, Kumari S, Shalini, Jayabalan G, Antihyperglycemic activity of Pithecellobium dules plant extracts on blood glucose levels of streptozocin-induced diabetic rats, Journal of Drug Delivery and Therapeutics. 2018; $8(2): 21-24$

DOI: http://dx.doi.org/10.22270/jddt.v8i2.1677

\section{*Address for Correspondence}

Dr. Ashutosh Upadhayay, Professor \& HOD, Department of Pharmacology, Alwar Pharmacy College, North Extension, MIA, Alwar, Rajasthan.301030, Mobile No: 9887769310

\section{INTRODUCTION}

Diabetes mellitus is an endocrine metabolic disorder characterized by hyperglycemia, altered lipids, carbohydrates, proteins metabolism and it increases risk of cardiovascular diseases complications ${ }^{1}$. The two forms of diabetes, type 1 and 2, differ in their basic mechanisms of development and in physiologic characteristics such as associations with obesity, age, and insulin. But, both types of the diabetes share the common characteristics of hyperglycemia, micro vascular and macro vascular complications. Moreover, the alterations of lipoproteins metabolism are involved to the pathogenesis of the cardiovascular disease in both forms of diabetes in a similar way ${ }^{2}$. Also, diabetes is usually accompanied by increased generation of free radicals or impaired antioxidant defenses. Oxidative stress is also responsible for the development and progression of diabetes and its complications ${ }^{3}$. Diabetes has a considerable impact on the health, life style, life 
expectancy of patients and its related complications are major healthcare problems. Currently, diabetes is controlled by handful of available drugs such as oral hypoglycemic agents and insulin, but they have their own limitations. Traditionally, many herbal medicines and medicinal plants have been used for the treatment of diabetes as an alternative medicine ${ }^{4,5,6,7}$. Presence of various phytoconstituents in medicinal plants is thought to act on a different series of targets by multiple modes and mechanisms. Hence, plants have the potential to impart therapeutic effect in complicated disorders like diabetes and its complications ${ }^{8}$. Screening of medicinal plants is one of the alternative and valid approaches in the drug development process because they contain diverse phytoconstituents which may give new drug leads and may be effective and safe in diabetes ${ }^{9}$. In India, traditionally numbers of plants are used to manage the diabetic conditions and their active principles were isolated but few plants have been scientifically studied ${ }^{10,11,12}$.

Pithecellobium dules (Fabaceae) Indian plant known as Jangal Jalebi. Leaves, inflorescence, bark and fruits of this plant are traditionally employed in several regions for medicinal purposes ${ }^{13}$. The present study was designed to test the antihyperglycemic effect of Pithecellobium dules plant extract on streptozocininduced diabetes.

\section{MATERIAL AND METHODS}

\section{Plant Material:}

The plant of Pithecellobium dules were collected from local area of Alwar district, Rajasthan, with the help of field botanist. The plant of $P$. dules has been authenticated from Rajasthan University, Jaipur, India. (Ref. RU/2017/652). The whole plant was dried initially under shade. It was preserved in a tightly closed container and powdered as per requirements.

\section{Preparations of Extracts:}

The dried whole plant was subjected to size reduction to a coarse powder by using dry grinder and passed through sieve. About 150g of this powder was packed into Soxhlet apparatus and extracted successively with petroleum ether, chloroform, and ethanol (yield 1.85\%, $1.76 \%, 1.90 \%$, respectively). The solvent was recovered by distillation in vacuum and extracts were stored in desiccators and used for subsequent experiments.

\section{Experimental animals}

Male wistar rats (150-200 g) were used to assess acute toxicity and antihyperglycemic activity. All animals were housed in standard laboratory conditions temperature $\left(22^{0} \mathrm{C} \pm 2\right)$ and humidity $(45 \pm 5) \%$ with $[12 \mathrm{~h}$ day: $12 \mathrm{~h}$ night cycle]. The standard laboratory diet was provided to the animals and they were allowed to drink water ad libitum. Studies were carried out after the approval of Institutional Animal Ethical Committee in accordance with institutional ethical guidelines for the care of laboratory animals of Alwar Pharmacy College, Alwar, Raj, India (approval no.- APC/IEAC/2017/RP001).

\section{Chemicals}

The estimation of biochemical parameters was carried out using commercially available kits (Primal Healthcare Limited, Lab Diagnostic Division, and Mumbai, India). STZ and other chemicals were procured from Himedia Laboratories, Mumbai, India.

\section{Acute toxicity study}

Acute oral toxicity study was performed as per Organization for Economic Cooperation and Development guidelines 423 (acute toxic classic method) ${ }^{14}$. After the oral administration of seed of $P$. dules $(2,000 \mathrm{mg} / \mathrm{kg})$, animals were observed individually at least once during the first $30 \mathrm{~min}$, periodically during the first $24 \mathrm{~h}$, with special attention given during the first $4 \mathrm{~h}$, and daily thereafter, they were observed for a total of 14 days for toxicity determination 14.

\section{Induction of experimental diabetes in rats}

STZ was dissolved in freshly prepared $0.1 \mathrm{M}$ cold citrate buffer ( $\mathrm{pH}$ 4.5) and administered by intraperitoneal route $(45 \mathrm{mg} / \mathrm{kg})$ to the overnight fasted rats ${ }^{15}$. After 6 h of STZ injection, rats were received $5 \%$ dextrose solution for the next $24 \mathrm{~h}$ to prevent STZ induced fatal hypoglycemia as a result of massive pancreatic insulin release after its administration. Diabetes was confirmed $72 \mathrm{~h}$ after induction by measurement of tail vein blood glucose levels using glucose meter by glucose oxidase-peroxidase method using strips. Diabetic rats were kept 7 days under standard laboratory condition for the stabilization of blood glucose levels ${ }^{16}$. After 7 days induction of diabetes, blood glucose was again determined and animals with a blood glucose level greater than 250 $\mathrm{mg} / \mathrm{dl}$ were selected for the study.

\section{Phytochemical screening:}

The preliminary phytochemical screening of the crude extract of $P$. dules was carried out in order to ascertain the presence of its constituents utilizing standard conventional protocols ${ }^{17}$.

\section{Experimental design}

The Streptozocin-induced diabetic wistar rats were randomly assigned into 6 groups (1-6) of six rats $(n=6)$ each as Follows, namely

Group 1- Non diabetic rats received normal saline 10 $\mathrm{ml} / \mathrm{kg}$ of body weight, per orally

Group 1- Diabetic rats received normal saline $10 \mathrm{ml} / \mathrm{kg}$ of body weight, per orally

Group2- Received glibenclamide $10 \mathrm{mg} / \mathrm{kg}$ of body weight, per orally

Group3- Received P. dules extract $150 \mathrm{mg} / \mathrm{kg}$ of body weight, per orally

Group4- Received P. dules extract $300 \mathrm{mg} / \mathrm{kg}$ of body weight, per orally

Group5- Received P. dules extract $600 \mathrm{mg} / \mathrm{kg}$ of body weight, per orally 


\section{Determination of blood glucose levels:}

Blood samples were collected by cutting the tail-tip of the rats, for blood glucose determination at intervals of 2, 4, 6 and 8 hours by the glucose-oxidase principle using the one touch basic instrument and results were reported as $\mathrm{mg} / \mathrm{dl}^{18,19}$.

\section{Statistical analysis:}

Blood glucose levels were expressed in $\mathrm{mg} / \mathrm{dl}$ as mean \pm SEM. The data were statistically analyzed using ANOVA with multiple comparisons versus control group. The values of $\mathrm{p}<0.01$ were considered as significant ${ }^{20}$. The criterion for statistical significance was considered as $\mathrm{P}$ value $<0.001$. The difference between test and controls were evaluated by student's ttest. $^{21}$

\section{RESULTS}

\section{Phytochemical analysis:}

Freshly prepared extracts were subjected to preliminary phytochemical screening test for various constituents. This revealed the presence of tannins, carbohydrate, terpenes, saponins, flavonoids and alkaloids.

\section{Acute toxicity study (LD50):}

The sign of toxicity were first noticed after 10-12 hours of extract administration. There was decreased locomotor activity and decreased in sensitivity to touch. Also there was decreased feed intake, and prostration after 20 hours of extract administration. The median lethal dose $\left(\mathrm{LD}_{50}\right)$ in rats was calculated to be 2,000 $\mathrm{mg} / \mathrm{kg}$ body weight.

\section{Anti diabetic study:}

Table 1: Effect of $P$. dulce on blood glucose level in streptozotocin induced diabetic male wister rats treated by various doses of acetone insoluble ethanolic extracts (acute study)

\begin{tabular}{|c|c|c|c|c|c|c|c|}
\hline \multirow{2}{*}{ Groups } & \multirow{2}{*}{ Treatment } & \multicolumn{6}{|c|}{ Blood glucose level mg/dl } \\
\hline & & Ohr & $2 \mathrm{hrs}$ & 4hrs & 6hrs & $8 \mathrm{hrs}$ & 24hrs \\
\hline I & $\mathrm{NC}$ & $67.16 \pm 3.44$ & $68.66 \pm 3.62$ & $66.16 \pm 3.74$ & $72.83 \pm 4.44$ & $72.13 \pm 3.40$ & $72.83 \pm 3.33$ \\
\hline II & $\mathrm{DC}$ & $377.83 \pm 8.04$ & $382.66 \pm 8.61$ & $386.33 \pm 9.84$ & $390.16 \pm 9.83$ & $394.83 \pm 9.48$ & $396.00 \pm 9.06$ \\
\hline III & GLB & $393.00 \pm 9.83$ & $255.33 \pm 6.18 * *$ & $218.16 \pm 5.47 * *$ & $155.50 \pm 6.26^{* *}$ & $227.00 \pm 6.23 * *$ & $320.66 \pm 6.47 * *$ \\
\hline IV & AIEE -150 & $401.50 \pm 8.33$ & $375.66 \pm 10.49$ & $319.50 \pm 8.47$ & $231.50 \pm 8.56^{*}$ & $279.66 \pm 9.95^{*}$ & $368.33 \pm 11.08$ \\
\hline $\mathrm{V}$ & AIEE -300 & $390.00 \pm 8.41$ & $354.00 \pm 8.15$ & $272.16 \pm 7.47 *$ & $214.16 \pm 9.74 * *$ & $262.83 \pm 8.32 * *$ & $353.50 \pm 10.38^{*}$ \\
\hline VI & AIEE -600 & $392.83 \pm 8.07$ & $292.33 \pm 7.28 * *$ & $218.66 \pm 6.88 * *$ & $188.50 \pm 6.14 * *$ & $253.00 \pm 7.46^{* *}$ & $348.00 \pm 9.31 * *$ \\
\hline
\end{tabular}

$\mathrm{n}=6, * \mathrm{p}<0.05$ - significant, $* \mathrm{p}<0.01$-more significant $\mathrm{v} / \mathrm{s}$ diabetic control, $\mathrm{SEM}=$ standard error mean, $\mathrm{SD}=$ standard deviation, $\mathrm{n}=$ number of animals

NC-Normal Control, DC- Diabetic Control, GLB-Glibenclamide, AIEE-150 -Acetone Insoluble Fraction of Ethanolic Extract of $P$. dulce $150 \mathrm{mg} / \mathrm{Kg}$ AIEE-300 -Acetone Insoluble Fraction of Ethanolic Extract of $P$. dulce $300 \mathrm{mg} / \mathrm{Kg}$, AIEE-600 -Acetone Insoluble Fraction of Ethanolic Extract of $P$. dulce $600 \mathrm{mg} / \mathrm{Kg}$

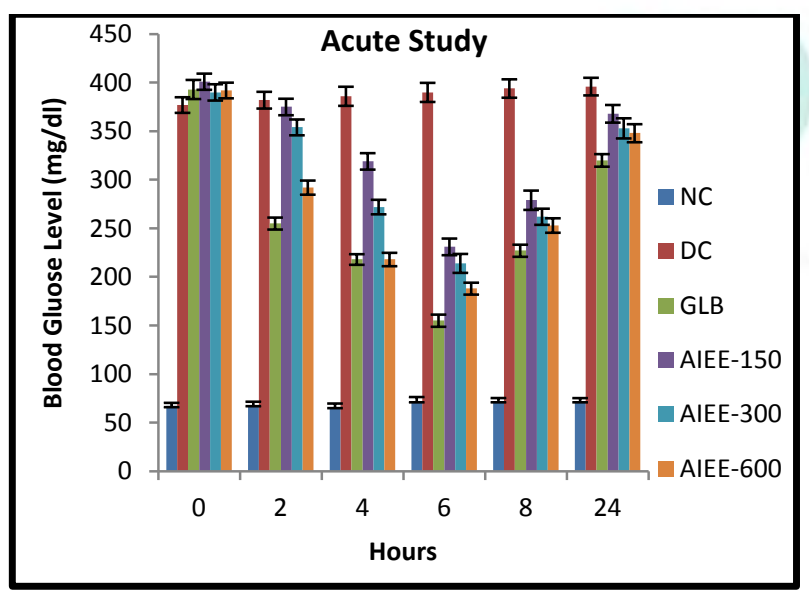

Graph: Effect of $P$. dulce on blood glucose level in streptozotocin induced diabetic rat (acute Study)

\section{DISCUSSION}

Medicinal plants are widely used by the populations of underdeveloped countries as alternative therapy. In India, hundreds of plants are used traditionally for the management and/or control of diabetes mellitus. Unfortunately only a few of such Indian medicinal plants have received scientific scrutiny. The present work was therefore designed to study the anti- hyperglycemic property of plant of $P$. dules extract in Streptozocin-diabetic rats. Streptozocin-induced hyperglycemia has been described as a useful experimental model to study the activity of hypoglycemic agents ${ }^{22}$. Streptozocin selectively destroyed the pancreatic insulin secreting $\beta$-cells, leaving less active cell resulting in a diabetic state ${ }^{23}$. Many secondary metabolites participate in a variety of anti-diabetic functions in vivo ${ }^{24}$. The change in blood glucose levels of diabetic rat at different time intervals after oral administration $P$. dules extract of at the doses of 150,300 , and $600 \mathrm{mg} / \mathrm{kg}$ as showed in Fig, 1 .

In relation to the diabetes rats that received 150, 300, and $600 \mathrm{mg} / \mathrm{kg}$ bodyweight of $P$. dules extract there was a significant $(\mathrm{p}<0.01)$ reduction in the blood glucose levels when compared to the control group after different time hours of extract administration as regard to the dose of $600 \mathrm{mg} / \mathrm{kg}$ body weight and the reference drug . In relation to the dose of 150 and $300 \mathrm{mg} / \mathrm{kg}$ body weight of the $P$. dules there was a less significant change in the blood glucose levels after different time hour of extract administration. In relation to the reference drug glibenclamide $10 \mathrm{mg} / \mathrm{kg}$ of body weight given orally. The dose of $600 \mathrm{mg} / \mathrm{kg}$ body weight was found to be more effective in the glycemic change after 6 hours of 
extract administration than the other two doses of the extract 150 and $300 \mathrm{mg} / \mathrm{kg}$ body weight. The extract might possess glibenclamide like effect on peripheral tissues either by promoting glucose uptake and metabolism or inhibiting hepatic gluconeogenesis. The phytochemical studies of $P$. dules extract revealed the presence of tannins, carbohydrate, terpenes, saponins, flavonoids and alkaloids ${ }^{25}$.

Effect of the flavonoids, quercetin and ferulic acid on pancreatic $\beta$-cells leading to their proliferation and secretion of more insulin have been proposed ${ }^{26,27}$. The presence of these constituents leads to antihyperglycemic activity caused by streptozocin in diabetic rats. The flavonoids present in $P$. dules may also be acting similarly thereby decreasing the high blood glucose levels of streptozocin-diabetic rats.

\section{REFERENCES}

1. Davis S, Insulin, oral hypoglycemic agents and the pharmacology of the endocrine pancreas. In: Brunton L, Lazo J, Parker K. (eds.) Goodman and Gilman's the pharmacological basis of therapeutics. New York: McGraw Hill; 2006, 1613-1646.

2. Howard BV, Lipoprotein metabolism in diabetes mellitus, J Lipid Res 1987; 28:613-628.

3. Maritim AC, Sanders RA, Watkins JB. Diabetes, oxidative stress, and antioxidants: a review, J Biochem Mol Toxicol, 2003; 17:24-38.

4. Mukherjee P, Maiti K, Mukherjee K, Houghton PJ, Leads from Indian medicinal plants with hypoglycemic potentials, J Ethnopharmacol 2006; 106:1-28.

5. Imran $M$, Khan $M$, Akhtar $R$, Ahmed $S$, Rageeb $M$, Antidiabetic and hypolipidemic effect of methanol extract of Stereospermum colais fruit in streptozotocin induced diabetic rats. Journal of Drug Delivery and Therapeutics, 2016; 6(4):41-47. doi:10.22270/jddt.v6i4.1272.

6. Malviya S, Vyas N, Joshi A, Kharia A, Malviya N, Pharmacological Assessment of Antidiabetic Potential of Hydroalcoholic Extract of Cassia fistula Linn. in Streptozotocin-induced Diabetic Rats. Journal of Drug Delivery and Therapeutics, 2017; 7(7):168-169. doi:10.22270/jddt.v7i7.1623.

7. Dubey K, Dubey R, Gupta R, Gupta A, Anti-Diabetic Potential of Aqueous, Methanolic and Saponin Extract of Leaves of Ziziphus nummlaria Linn., Journal of Drug Delivery and Therapeutics, 2017; 7(7):173-174. doi:10.22270/jddt.v7i7.1625.

8. Tiwari A, Rao J, Diabetes mellitus and multiple therapeutic approaches of phytochemicals: present status and future prospects, Curr Sci, 2002; 83:30-38.

9. Varier PS, Indian medicinal plants compendium of 500 species, Hyderabad: Orient Longman Ltd; 1995.

10. Khandelwal KR, Practical Pharmacognosy, Nirali Prakashan, Pune, 2005, 29-31.

11. Niranjan $\mathrm{P}$, Kaushal C, Jain S, Pharmacological investigation of leaves of Polypodium decumanum for antidiabetic activity, Journal of Drug Delivery and Therapeutics, 2017; 7(4)"69-72. doi:10.22270/jddt.v7i4.1468

12. Manivannan R, Shopna R, Antidiabetic activity of Calotropis gigantea white flower extracts in alloxan induced diabetic rats. Journal of Drug Delivery and Therapeutics, 2017; 7(3):106-111. doi:10.22270/jddt.v7i3.1447

13. Nandkaran KM, The Indian Materia Medica, Bombay Popular Prakashan, Mumbai,209.
In conclusion, the experiment evidence obtained in the present laboratory animal study indicate that plant of $P$. dules extract possess anti-hyperglycemic properties which suggest the presence of biologically active components which may be worth further investigation and elucidation.

\section{ACKNOWLEDGEMENTS}

The authors wish to thank Dr. V. K. Agrawal, Chairman, IET Group of Institution, Alwar for encouragement throughout the period of this research work. I would also like to give special thanks to Mr. Gaurav soni and Mr. Nitin Jumnani for his inspiration \& providing necessary facilities to carry out this research work.

14. OECD: OECD guidelines for testing of chemicals 423: acute oral toxicity-acute toxic class method. Paris: OECD; 2001.

15. Ramachandran S, Asokkumar K, Uma Maheswari M, Ravi TK, Sivashanmugam AT, Saravanan S, Investigation of antidiabetic, antihyperlipidemic, and in vivo antioxidant properties of Sphaeranthus indicus Linn. in type 1 diabetic rat: an identification of possible biomarkers, Evid Based Complement Alter. Med., 2011; 571-721.

16. Tanko Y, Yerima M, Mahdi MA, Yaro AH, Musa KY, Mohammed A, Hypoglycemic activity of methanolic stem bark of Adansonnia digitata extract on blood glucose levels of streptozotocin-induced diabetic wistar rats, Int J Appl Res Nat Prod, 2008; 1:32-36.

17. Trease GE, Evans MC, Textbook of Pharmacognosy, London Bailliere, Tindall; 1983, 683-684.

18. Beach EF, Turner JJ, An enzymatic method for glucose determination uptake in body fluids, Clin Chem, 1958, 4,462468.

19. Ortiz Andrade R R, Garcia Jimenez S, Castillo Espina P, Avila, GR, Molina RV, Alpha glucosidase inhibitory activity of the methanolic extract from Tournefortia hartwegiana: an anti-hyperglycemic agent, Indian $\mathbf{J}$ of Pharmacol, 2007, 109,48-53.

20. Duncan RC, Knapp RG, Miller MC, Test of hypothesis in population. In: Introductory Biostatistics for the health sciences, John Wiley and Sons Inc. NY, 1977, 71-96.

21. Rheney CC, Kirk KK, Performance of three blood glucose meters, Ann Pharmacother, 2000, 34 ,3 , 317-21.

22. Szkudelski T, The mechanism of Alloxan and Streptozocin action in $\beta$ cell of the rats pancreas, Physiol Res, 2001, 50,53646.

23. Kamchouing P, Sokeng DS, Moundipa, FP, Watcho P, Jatsa $\mathrm{BH}$, Lontsi ,. Protective role of Anacardium occidentale extract against streptozocin- induced in rats, J. Ethnopharmacol, 1998, 62,55-99.

24. Kako M, Miura T, Nishiyama Y, Ichimaru M, Moriyasu K, Hypoglycemic activity of some triterpenoid glycosides, J. Nat. Prod, 1997 , 60, 604-605.

25. Marles JR, Farnsworth NR, Antidiabetic plants and their active constituents,Phytomedic, 1952, 2, 123-89.

26. Mahesh T, Menon PV, Quercetin alleviates oxidative stress in streptozotocin induced diabetic rats, Phytotherapy Research, 2004, 18, 123-127.

27. Balasubashini M, Rukkumani R, Viswanathan P, Menon PV, Ferulic acid alleviates lipid peroxidation in diabetic rats, Phytotherapy Research, 2004, 18, 310-314. 